Open Access to Pharmaceutical and Medical Research

(C) 2011-18, publisher and licensee JDDT, This is an Open Access article which permits unrestricted non-commercial use, provided the original work is properly cited

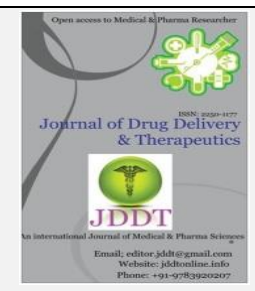

Open Access

Research Article

\title{
Design, Development and Characterization of Nifedipine Microspheres
}

\author{
Arun Kumar Chalamalasetty', Narender Boggula², Nirosha Bolledla ${ }^{2}$, Vasudha Bakshi², Himabindu \\ Peddapalli $^{* 2}$
}

${ }^{1}$ Department of Pharmaceutics, Jangaon Institute of Pharmaceutical Sciences, Yeshwanthpur, Jangaon, Telangana, INDIA-506 167

${ }^{2}$ Department of Pharmaceutics, School of Pharmacy, Anurag Group of Institutions, Venkatapur, Ghatkesar, Telangana, INDIA-500 088

\begin{abstract}
Back ground: Nifedipine is a calcium channel blocker and is used in treatment of angina of angina pectoris and hypertension. Nifedipine readily and almost completely absorbed from GIT, but undergoes first pass metabolism, resulting in low oral bioavailability is about $50 \%$
\end{abstract}

Aim: The aim of the present study was to prepare and evaluate the microspheres of nifedipine with a goal of improving the bioavailability and giving a prolonged release of drug.

Method: Emulsification (o/w) solvent evaporation method was employed in the preparation of nifedipine microparticles using ethyl cellulose and combination of ethyl cellulose and hydroxypropyl methylcellulose as the polymers.

Results: FT-IR spectra of physical mixture showed no significant shifting of the peaks therefore it reveals that the drug is compatible with the polymer used. The percentage yield obtained in all the formulations was good and in the range of 59.25-94.44\%. Among all the formulations, formulation with combination of ethyl cellulose and hydroxypropyl methylcellulose polymers M9 showed high amount of drug release i.e. $(91.23 \%)$ in $12 \mathrm{hrs}$. Drug release from microspheres with small mean particle size was faster than those with large mesh particle size and followed Higuchi model of kinetics.

Conclusion: The obtained results could be used as essence to develop microspheres, which bypasses first-pass metabolism and results in the improvement of bioavailability. Hence, the present study has been a satisfactory attempt to formulate microspheres of nifedipine, with a view of improving its oral bioavailability and giving a prolonged release of drug.

Keywords: Microspheres, nifedipine, hydroxypropyl methylcellulose E5, ethyl cellulose.

Article Info: Received 24 March 2019; $\quad$ Review Completed 24 April 2019; $\quad$ Accepted 01 May $2019 ; \quad$ Available online 15 May 2019

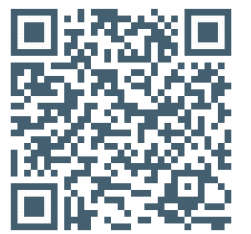

\section{Cite this article as:}

Chalamalasetty AK, Narender B, Nirosha B, Vasudha B, Himabindu P, Design, Development and Characterization of Nifedipine Microspheres, Journal of Drug Delivery and Therapeutics. 2019; 9(3):138-146

http://dx.doi.org/10.22270/jddt.v9i3.2627

Himabindu Peddapalli, Assistant Professor, Department of Pharmaceutics, School of Pharmacy, Anurag Group of Institutions, Venkatapur, Ghatkesar, Telangana, INDIA-500 088.

\section{INTRODUCTION}

Microencapsulation is one of the newly developed techniques. Microencapsulation for oral use has been employed to sustain the drug release, and to reduce or eliminate gastrointestinal tract irritation. In addition, multiparticulate delivery systems spread out more uniformly in the gastrointestinal tract. This results in more reproducible drug absorption and reduces local irritation when compared to single-unit dosage forms such as no disintegrating, polymeric matrix tablets. Unwanted intestinal retention of the polymeric material, which may occur with matrix tablets on chronic dosing, can also be avoided. Microencapsulation is used to modify and retard drug release. Due to its small particle size, are widely distributed throughout the gastrointestinal tract which improves drug absorption and reduces side effects due to localized build-up of irritating drugs against the gastrointestinal mucosa ${ }^{1}$.

Microencapsulation is a process of incorporating drugs into small size multi particulate units. As a process it is a means of applying relatively thin coatings to small particles of solids or droplets of liquids. Microencapsulation developed for use in medicine consists of solid or liquid core material containing one or more drugs enclosed in coating material 2 . The core may also be referred as nucleus and the coating as wall or sheet. In the present study microencapsulation was selected as a method to design sustained release dosage forms because it is a rapidly expanding technology. In this method relatively thin coatings are applied to small particles of solids or droplets of liquids and dispersions. Microencapsulation also used in converting liquids to solids, altering colloidal and surface properties, providing 
environmental protection and in controlling the release characteristics or availability of coated materials.

Nifedipine is a calcium channel blocker available in yellow, crystalline powder, thermostable and non-hygroscopic in nature. It is insoluble in water, freely soluble in acetone and sparingly soluble in ethanol3,4. The bioavailability of nifedipine is $50 \%$ and it binds with plasma to about $96 \%$. Its half-life is $2-3 \mathrm{hrs}$ and effective concentration is about $15 \mathrm{ng} / \mathrm{ml}$. Nifedipine readily and almost completely absorbed from GIT, but undergoes first pass metabolism. The volume of distribution after oral administration was found to be $1.32 \mathrm{~L} / \mathrm{kg}^{5}$. Nifedipine is used in treatment and prophylaxis of angina of angina pectoris, Reynaud's syndrome and hypertension. Therefore, preparation of a sustained release formulation may be desirable.

\section{MATERIALS AND METHODS}

\section{Materials}

Nifedipine was a gift sample from Medreich Ltd., Bengaluru, Karnataka, India. Hydroxypropyl methylcellulose E5 and ethyl cellulose were gift samples from Dr. Reddy's Laboratories, Hyderabad, Telangana, India. Dichloromethane AR and acetone were procured from Merck Ltd., Mumbai, India. PVP was purchased from Fine chemicals, Chandigarh, India. Disodium hydrogen Phosphate was purchased from SD Fine Chem Ltd., Mumbai, India.

\section{Methods}

\section{Pre-formulation studies}

\section{Organoleptic properties}

The organoleptic character of the drug like color, odor and appearance play an important role in the identification of the sample, and hence they should be recorded in a descriptive terminology.

\section{Solubility studies}

It is important to know about solubility characteristics of a drug in aqueous systems, since they must possess some limited aqueous solubility to elicit a therapeutic response. Solubility was carried out in water, $0.1 \mathrm{~N} \mathrm{HCl}, 0.1 \mathrm{~N} \mathrm{NaOH}, 6.8$ $\mathrm{pH}$ phosphate buffer, $7.4 \mathrm{pH}$ phosphate buffer.

\section{Determination of melting point}

Melting point of the drug was determined by capillary tube method. Take a small amount of the drug in a capillary tube closed at one end and was placed in Thieles melting point apparatus and the temperature at which the drug melts were noted. Average of triplicate readings was taken.

\section{Determination of absorption maxima values $\left(\lambda_{\max }\right)$}

Standard stock solution of drug $(100 \mu \mathrm{g} / \mathrm{ml})$ was prepared in $7.4 \mathrm{pH}$ phosphate buffer. For the selection of analytical wavelength, solution of nifedipine of concentration $30 \mu \mathrm{g} / \mathrm{ml}$ was prepared by appropriate dilution of standard stock solution with phosphate buffer $\mathrm{pH} 7.4$ and scanned in the spectrum range from 200 to $400 \mathrm{~nm}$. From this overlain spectrum of the drug, the wavelength with maximum absorbance was chosen for further analysis.

\section{Construction of standard calibration curve of nifedipine:}

Preparation of standard calibration curve of nifedipine in $7.4 \mathrm{pH}$ phosphate buffer

\section{Procedure:}

\section{Preparation of standard solution}

1st Stock: $1000 \mu \mathrm{g} / \mathrm{ml}$ solution of nifedipine was prepared by dissolving $100 \mathrm{mg}$ of nifedipine in $10 \mathrm{ml}$ methanol and the volume was made up to $100 \mathrm{ml}$ with $7.4 \mathrm{pH}$ phosphate buffer.

$2^{\text {nd }}$ Stock: Pipette $10 \mathrm{ml}$ of above solution into another $100 \mathrm{ml}$ of volumetric flask and the volume was made up to mark with the $7.4 \mathrm{pH}$ phosphate buffer. (i.e.: $100 \mu \mathrm{g} / \mathrm{ml}$ in 7.4 pH buffer).

The above second stock solution was serially diluted with 7.4 $\mathrm{pH}$ phosphate buffer to get the final concentrations of 10, 20, $30,40,50$ and $60 \mu \mathrm{g} / \mathrm{ml}$. The absorbance of each concentration was measured $254 \mathrm{~nm}$ using UV-Visible spectrophotometer and graph was plotted against the concentration and absorbance ${ }^{6}$.

\section{Drug and excipients compatibility study}

To investigate any possible interactions between the drug and excipients used, the FT-IR spectra of pure nifedipine and its physical mixture with ethyl cellulose and hydroxylpropyl methylcellulose were carried out using Bomem FT-IR MB-II spectrophotometer. The samples were prepared as $\mathrm{KBr}$ (potassium bromide) disks compressed under a pressure of $10 \mathrm{Ton} / \mathrm{nm}^{2}$. The wave number selected ranged between 400 and $4800 \mathrm{~cm}^{-1}$.

\section{Preparation of nifedipine microspheres}

Emulsification (o/w) solvent evaporation method was employed in the preparation of nifedipine microparticles using ethyl cellulose and combination of ethylcellulose and hydroxylpropylmethylcellulose as the polymers. Polymer was dissolved in $10 \mathrm{ml}$ of dichloromethane. To this $45 \mathrm{mg}$ of drug was added and mixed thoroughly. The above organic phase was added drop wise to $100 \mathrm{ml}$ of $1 \%$ PVA solution under magnetic stirrer at $800 \mathrm{rpm}$ by keeping at $40{ }^{\circ} \mathrm{C}$ and stirring is continued until total evaporation of dichloromethane ${ }^{7,8}$. Then the solution was filtered and product was dried. Different formulations were prepared by taking different drug to polymer ratios $1: 0.5,1: 1,1: 1.5,1: 2$, $1: 2.5,1: 3,1: 3.5$ and $1: 4$ and $1: 1,1: 2,1: 3$ and $1: 4$ of ethylcellulose and combination of equal ratios of ethylcellulose and hydroxylpropylmethylcellulose respectively. The prepared particles were evaluated for particle size, encapsulation efficiency, drug-polymer interaction by FT-IR and in-vitro drug release. 


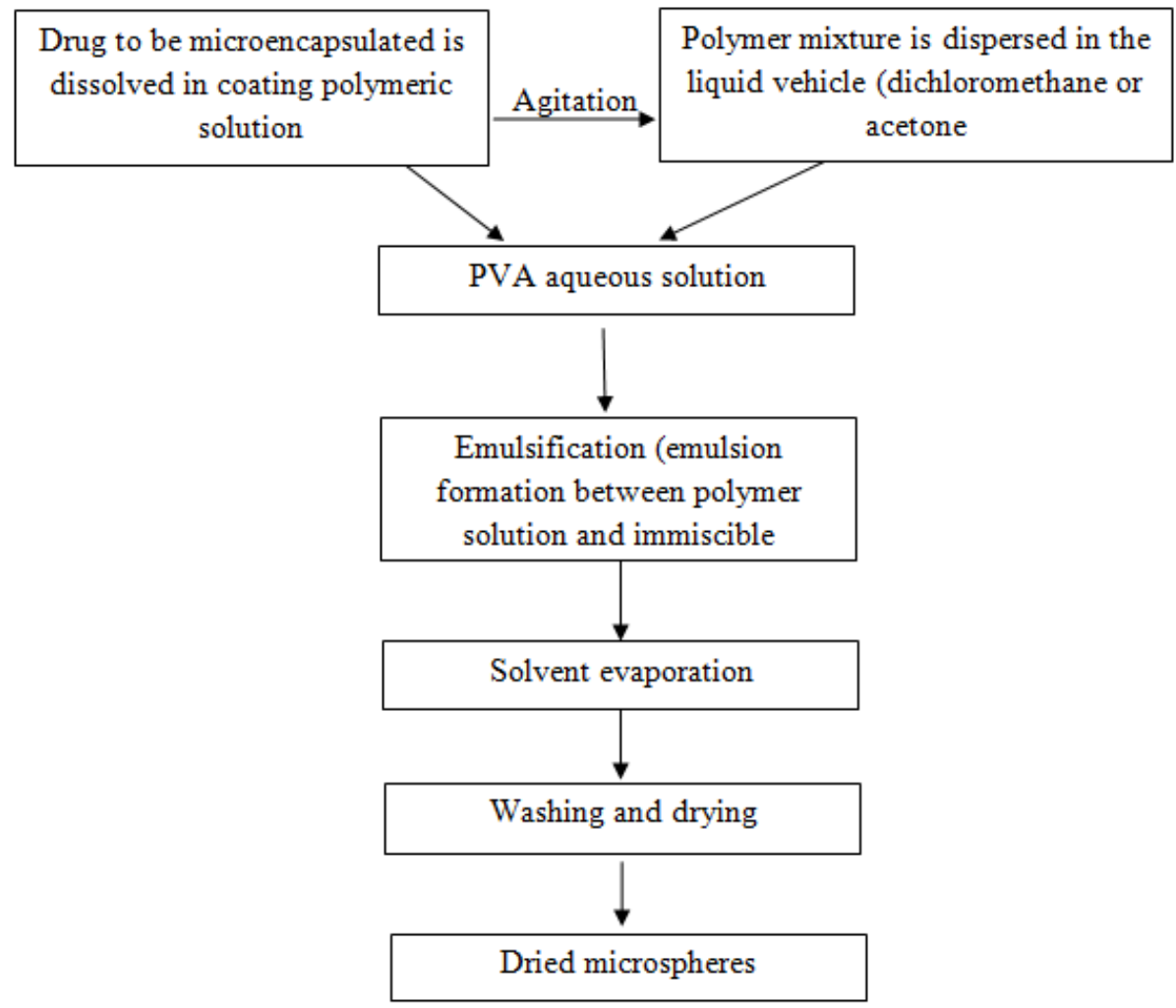

Figure 1: Formulation of nifedipine microspheres

Table 1: Formulation composition of nifedipine microspheres

\begin{tabular}{|c|c|c|c|c|c|c|c|}
\hline $\begin{array}{c}\text { Formulation } \\
\text { code }\end{array}$ & $\begin{array}{c}\text { Drug( } \\
\mathbf{m g})\end{array}$ & $\begin{array}{c}\text { HPMC E5 } \\
\text { (mg) }\end{array}$ & $\begin{array}{c}\text { Ethyl } \\
\text { cellulose } \\
\text { N50 (mg) }\end{array}$ & $\begin{array}{c}\text { DCM } \\
\text { (ml) }\end{array}$ & $\begin{array}{c}\text { Acetone } \\
\text { (ml) }\end{array}$ & $\begin{array}{c}\text { PVA } \\
\text { (\%) }\end{array}$ & $\begin{array}{c}\text { Drug: } \\
\text { Polymer }\end{array}$ \\
\hline $\mathrm{M}_{1}$ & 45 & 22.5 & - & 10 & - & 1 & $1: 0.5$ \\
\hline $\mathrm{M}_{2}$ & 45 & 45 & - & 10 & - & 1 & $1: 1$ \\
\hline $\mathrm{M}_{3}$ & 45 & 67.5 & -- & 10 & - & 1 & $1: 1.5$ \\
\hline $\mathrm{M}_{4}$ & 45 & 90 & - & 10 & - & 1 & $1: 2$ \\
\hline $\mathrm{M}_{5}$ & 45 & 112.5 & - & 10 & - & 1 & $1: 2.5$ \\
\hline $\mathrm{M}_{6}$ & 45 & 135 & - & 10 & - & 1 & $1: 3$ \\
\hline $\mathrm{M}_{7}$ & 45 & 157.5 & - & 10 & - & 1 & $1: 3.5$ \\
\hline $\mathrm{M}_{8}$ & 45 & 180 & - & 10 & - & 1 & $1: 4$ \\
\hline $\mathrm{M}_{9}$ & 45 & 22.5 & 22.5 & 5 & 5 & 1 & $1: 1$ \\
\hline $\mathrm{M}_{10}$ & 45 & 45 & 45 & 5 & 5 & 1 & $1: 2$ \\
\hline $\mathrm{M}_{11}$ & 45 & 67.5 & 67.5 & 5 & 5 & 1 & $1: 3$ \\
\hline $\mathrm{M}_{12}$ & 45 & 90 & 90 & 5 & 5 & 1 & $1: 4$ \\
\hline
\end{tabular}

\section{Characterization of microspheres ${ }^{9-12}$}

\section{Percentage yield}

Microspheres dried at room temperature were weighed and the yield of microspheres was calculated using the formula 11,12 .

Percentage yield $=\frac{\text { The amount of microspheres obtained }}{\text { The amount }(\mathrm{gm}) \text { of non }- \text { volatile material taken }} \times 100$

\section{Encapsulation Efficiency}

To determine encapsulation efficiency, $100 \mathrm{mg}$ accurately weighted microspheres were washed and dissolved in $100 \mathrm{ml}$ with phosphate buffer $\mathrm{pH} 7.4$ solution. The microspheres were kept to soak for overnight. After $12 \mathrm{hrs}$ the solution was filtered through membrane filter. The volume was made up to $100 \mathrm{ml}$ with phosphate buffer $\mathrm{pH} 7.4$ and analyzed for drug content spectrophotometrically at 254 $\mathrm{nm}^{13}$.
Entrapment Efficiency

$=\frac{\text { Estimated } \% \text { amount of drug encapsulated }}{\text { Theoretical } \% \text { drug content in microspheres }}$ X100

\section{Determination of mean particle size of microspheres}

Particle size distribution of microspheres was carried out by optical microscopy. A minute quantity of dried microspheres was suspended in glycerin and the particle size of 100 microspheres was determined in each batch and the mean particle size was calculated. The average particle size was determined by using the Edmondson's equation ${ }^{9}$.

$$
\text { Edmondson's equation } \mathrm{D}=\frac{\text { Snd }}{n}
$$

\section{Scanning electron microscopy (SEM)}

For the external morphology studies, air dried particles were visualized using scanning electron microscopy (FEI-Quanta $200 \mathrm{~F}$ ) operating at $15 \mathrm{kv}$. The samples were mounted on a 
metal slab with double adhesive tape and coated with platinum under vacuum ${ }^{9-11}$.

\section{In-vitro release studies}

In-vitro release profile for microspheres performed using USP type 1 dissolution apparatus ${ }^{11,12}$. Sample equivalent to $45 \mathrm{mg}$ of nifedipine was added to $900 \mathrm{ml}$ phosphate buffer of $\mathrm{pH} 7.4$ at $37 \pm 0.5{ }^{\circ} \mathrm{C}$ and stirred at $100 \mathrm{rpm}$. Aliquot of $5 \mathrm{ml}$ was withdrawn at time intervals of $0.5,1,1.5,2,2.5,3,4,5,6$, $7,8,10$ and $12 \mathrm{hrs}$. The withdrawn volume was replenished with the same volume of dissolution medium in order to keep the total volume constant. The absorbance of the samples was measured at $254 \mathrm{~nm}$ using phosphate buffer of pH 7.4 as blank. Results of in-vitro drug release studies obtained from absorbance data were tabulated and shown graphically as Cumulative \% drug released Vs Time.

\section{Kinetics analysis of dissolution data}

There are a number of kinetic models, which described the overall release of drug from the dosage forms ${ }^{14}$. Data obtained from the in-vitro release was fit into different equations and kinetic models to explain the release kinetics of nifedipine from these microspheres. The kinetic models used were a zero-order equation, first order equation, Higuchi and Korsmeyer-Peppas model. Higuchi model is the most widely used model to describe drug release from pharmaceutical matrices system ${ }^{15}$.

The Peppas model is widely used, when the release mechanism is not well known and when more than one type of release is involved. To find out the mechanism of drug release, drug release data were fitted in Korsmeyer-Peppas model ${ }^{16}$. To study the diffusional release mechanism, data obtained from in-vitro drug release studies were plotted against log cumulative percentage drug release versus log time. The value of $n$ was estimated by linear regression of $\log \mathrm{Mt} / \mathrm{M} \infty$ versus $\log \mathrm{t}$.

$$
\frac{\mathrm{Mt}}{M \infty}=\mathrm{Kt}^{\mathrm{n}}
$$

Where,

$\frac{M t}{M \infty}$ is fraction of drug released at time $t$.

$\mathrm{t}$ is release time,

$\mathrm{K}$ is Kinetic constant (incorporating structural and geometric characteristics of preparation),

$\mathrm{n}$ is Diffusional exponent indicative of the mechanism of the drug release.

\section{RESULTS AND DISCUSSION}

\section{Preformulation studies}

The solubility of drug in water, $0.1 \mathrm{~N} \mathrm{HCl}, 0.1 \mathrm{~N} \mathrm{NaOH}, 6.8 \mathrm{pH}$ phosphate buffer, $7.4 \mathrm{pH}$ phosphate buffer were determined and results are shown in Table 2. The organoleptic properties of nifedipine were performed and physical appearance was good, elegant and results were compiles with pharmacopoeia values of drug characteristics. The melting point of drug was determined and was found to be $172-174{ }^{\circ} \mathrm{C}$.

Table 2: Solubility studies of nifedipine

\begin{tabular}{lll}
\hline S. No. & Medium & Solubility \\
\hline 1 & Water & $29 \mathrm{mg} / \mathrm{ml}$ \\
2 & $0.1 \mathrm{~N} \mathrm{HCl}$ & $15 \mathrm{mg} / \mathrm{ml}$ \\
3 & $0.1 \mathrm{~N} \mathrm{NaOH}$ & $18 \mathrm{mg} / \mathrm{ml}$ \\
4 & $6.8 \mathrm{pH}$ phosphate buffer & $11 \mathrm{mg} / \mathrm{ml}$ \\
5 & $7.4 \mathrm{pH}$ phosphate buffer & $10 \mathrm{mg} / \mathrm{ml}$ \\
\hline
\end{tabular}

ISSN: 2250-1177

\section{Determination of absorption maximum values}

An UV-Spectrophotometric method was used for determination of absorption maxima. The $\lambda_{\max }$ of nifedipine $(30 \mu \mathrm{g} / \mathrm{ml})$ in $7.4 \mathrm{pH}$ phosphate buffer was scanned in UVVisible Spectrophotometer in the wavelength range of 200$400 \mathrm{~nm}$ and found to have maximum absorbance at $254 \mathrm{~nm}$.

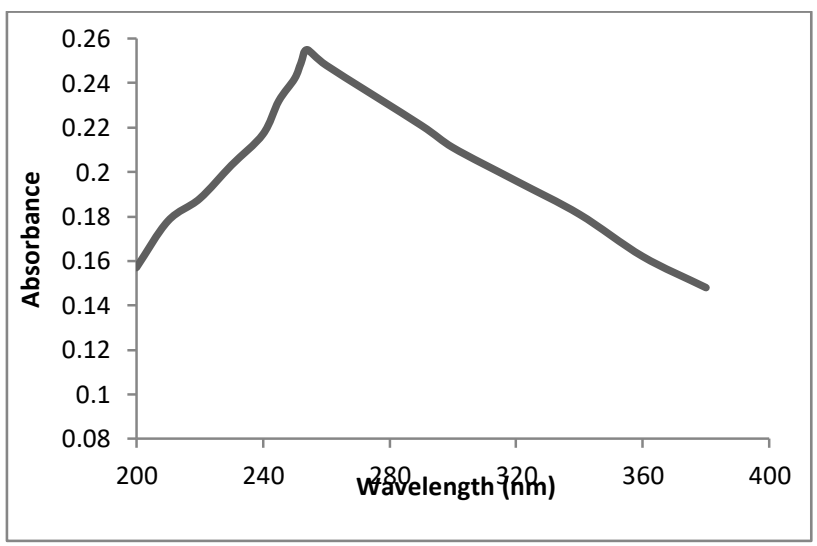

Figure 2: UV absorption spectrum of nifedipine in phosphate buffer pH 7.4

Preparation of standard calibration graph of nifedipine in pH 7.4 phosphate buffer

The solutions of nifedipine were prepared in phosphate buffer $\mathrm{pH} 7.4(10-60 \mu \mathrm{g} / \mathrm{ml})$ and the absorbance of resulting solutions was measured at $254 \mathrm{~nm}$ using UV spectrophotometer. The calibration curve showed a good linearity with correlation coefficient of $\mathrm{R}^{2} 0.999$.

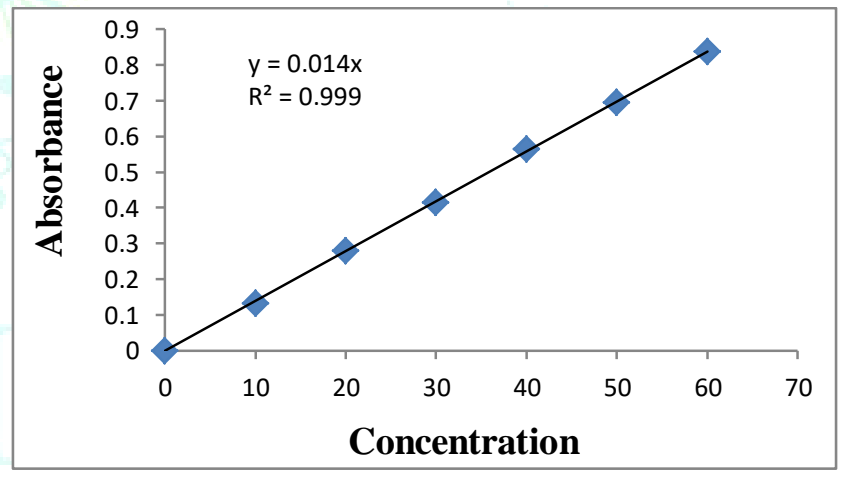

Figure 3: Standard graph of nifedipine in buffer pH 7.4

\section{Drug and excipients compatibility studies}

\section{Fourier Transform Infra-Red Spectroscopy (FT-IR)}

FT-IR spectroscopy was used to ensure that no chemical interactions between the drugs and polymer had occurred. The presence of interaction is detected by the disappearance of important functional group of the drug. The FT-IR spectra of nifedipine and polymer mixture showed several characteristic peaks. The FT-IR spectrum of pure nifedipine showed the characteristic peaks at wave numbers of 3320 $\mathrm{cm}^{-1}$ due to $>\mathrm{N}-\mathrm{H}$ stretching ( $>\mathrm{N}-\mathrm{H}$ of pyridine), at $1680 \mathrm{~cm}^{-1}$ due $(\mathrm{N}=0)_{2}$ asymmetric stretching (Aryl-NO) 2 , at $1220 \mathrm{~cm}^{-1}$ is due to $(\mathrm{N}=\mathrm{O})_{2}$ symmetric stretching (Aryl- $\left.\mathrm{NO}_{2}\right)$ and at $1520 \mathrm{~cm}^{-1}$ due to asymmetric carboxylate anion confirming the drug structure. The spectrum of nifedipine and polymer mixture also showed the characteristic peaks for nifedipine indicating no interaction between the drug and polymers used. This indicates that there is no chemical interaction between drug and polymer mixture, that the molecular structure of nifedipine remained completely intact. 


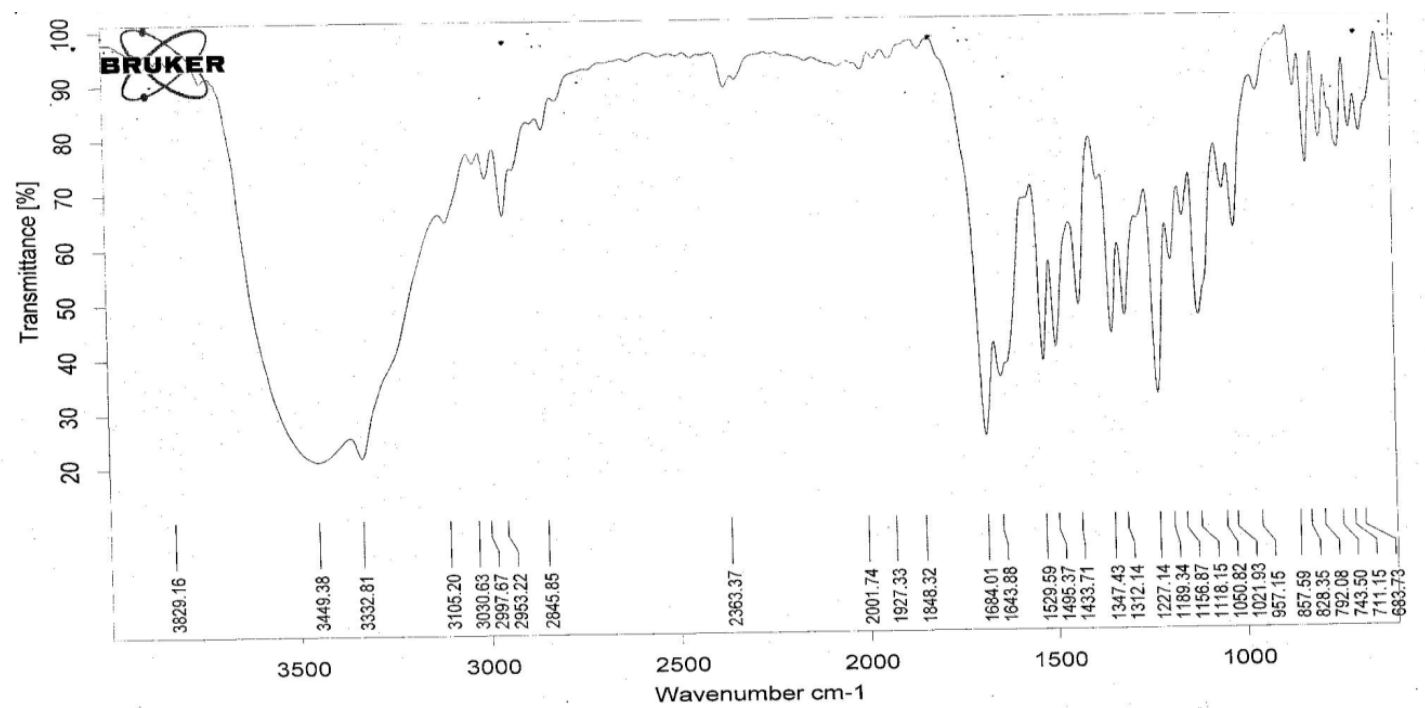

Figure 4: FT-IR spectrum of pure drug (nifedipine)

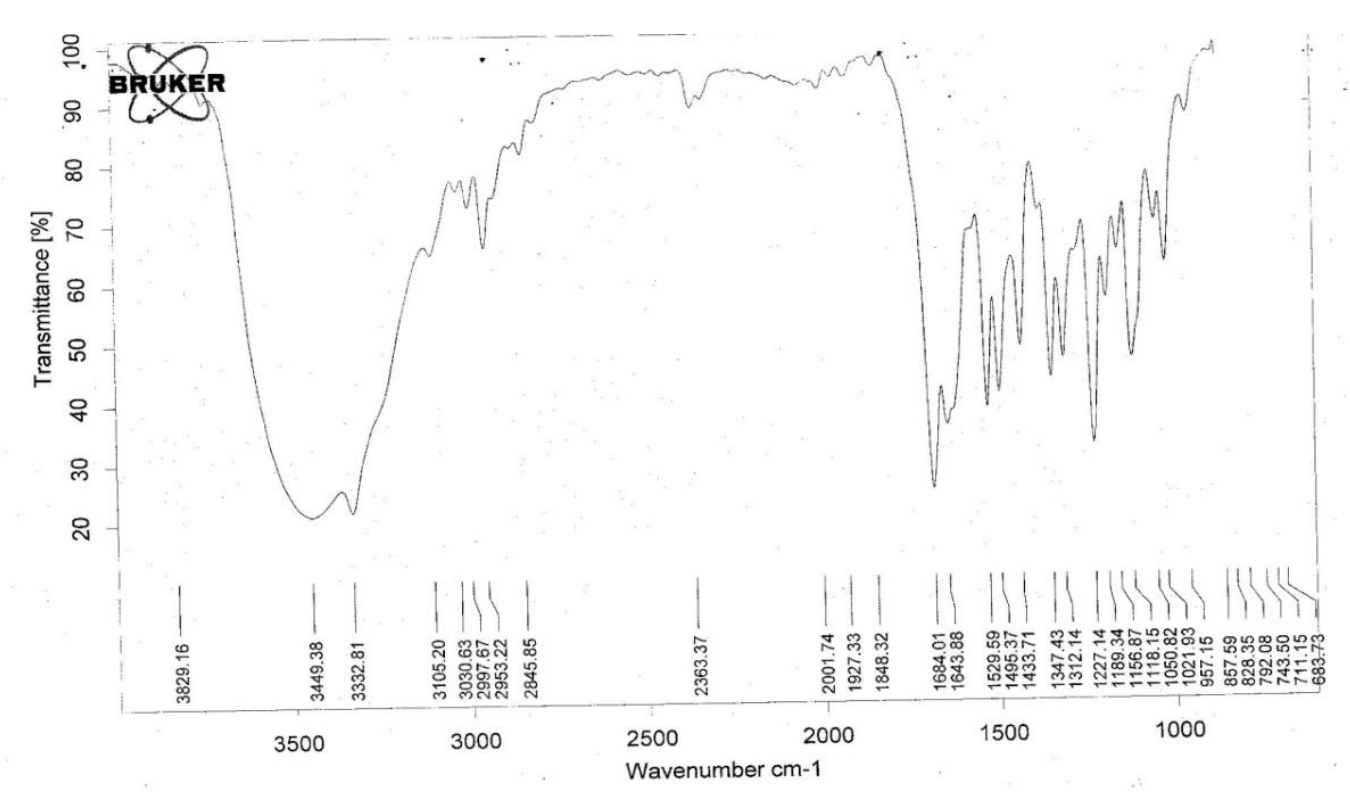

Figure 5: FT-IR spectrum of mixture of drug and polymers

\section{Percentage yield}

Percentage yield of microspheres is calculated and the percentage yield for all the ratios of microspheres were found to be in the range of 59.25-93.33\% and $60.55-94.44 \%$ for ethylcellulose and combination of ethylcellulose and hydroxypropyl methylcellulose respectively in which batch $\mathrm{MP}_{12}$ shows highest percentage yield $94.44 \%$. The loss of material during preparation of microspheres may be due to process parameters as well as filtration of microspheres. Percentage yield of all batches is shown in Table 3.

\section{Encapsulation efficiency}

The encapsulation efficiency of all the formulations was found to be in the range of $65.87-94.75 \%$ and $70.15-95.23 \%$ for formulations composed of ethyl cellulose and combination of ethylcellulose and hydroxypropyl methylcellulose respectively in which batch $\mathrm{MP}_{12}$ shows highest entrapment efficiency $95.23 \%$ and batch $\mathrm{MP}_{1}$ shows lowest entrapment efficiency $65.87 \%$. From the results it was seen that as the polymer concentration increased, viscosity of the dispersed phase increased, the encapsulation efficiency increased. This may be because of the availability of high amount of polymer to encapsulate the drug. The values of percentage encapsulation efficiency were shown in Table 3.

\section{Particle size determination}

The mean particle size of microspheres containing ethyl cellulose was found to be $133.5 \mu \mathrm{m}, 157.4 \mu \mathrm{m}, 189.3 \mu \mathrm{m}$, $200.5 \mu \mathrm{m}, 215.6 \mu \mathrm{m}, 223.5 \mu \mathrm{m}, 234.7 \mu \mathrm{m}, 246.1 \mu \mathrm{m}$ for $\mathrm{MP}_{1}$ to $\mathrm{MP}_{8}$ batches and mean particle size of microspheres containing ethylcellulose and hydroxypropyl methylcellulose combination was found to be $210.1 \mu \mathrm{m}$, $235.4 \mu \mathrm{m}, 243.9 \mu \mathrm{m}, 250.6 \mu \mathrm{m}$ for $\mathrm{MP}_{9}$ to $\mathrm{MP}_{12}$ batches respectively. In which $\mathrm{MP}_{12}$ shows highest particle size. As the polymer ratio increased the size of the particles increased. This may be because of viscosity of the polymer solution which increases as the polymer concentration increases and availability of high amount of polymer to coat the drug particles and deposition of many polymer layers. 
Table 3: Particle size, \% encapsulation efficiency and percentage yield of microspheres

\begin{tabular}{|c|c|c|c|}
\hline Formulation & $\begin{array}{c}\text { Particle size } \\
(\mu \mathrm{m})\end{array}$ & $\begin{array}{l}\text { Encapsulation } \\
\text { efficiency (\%) }\end{array}$ & $\begin{array}{c}\text { Percentage yield } \\
(\%)\end{array}$ \\
\hline MP1 & $133.5 \pm 1.25$ & $65.87 \pm 1.56$ & 59.25 \\
\hline $\mathbf{M P}_{2}$ & $157.4 \pm 1.34$ & $67.13 \pm 1.84$ & 63.88 \\
\hline $\mathrm{MP}_{3}$ & $189.3 \pm 1.28$ & $68.24 \pm 0.97$ & 68.88 \\
\hline $\mathrm{MP}_{4}$ & $200.5 \pm .87$ & $68.55 \pm 2.34$ & 74.07 \\
\hline $\mathrm{MP}_{5}$ & $215.6 \pm 2.34$ & $74.44 \pm 1.39$ & 78.73 \\
\hline $\mathrm{MP}_{6}$ & $223.5 \pm 1.84$ & $79.04 \pm 1.52$ & 83.33 \\
\hline $\mathbf{M P}_{7}$ & $234.7 \pm 1.57$ & $86.17 \pm 1.13$ & 91.35 \\
\hline MP8 & $246.1 \pm 0.96$ & $94.75 \pm 1.40$ & 93.33 \\
\hline $\mathrm{MP}_{9}$ & $210.1 \pm 1.23$ & $70.15 \pm 2.15$ & 60.55 \\
\hline $\mathbf{M P}_{10}$ & $235.4 \pm 1.45$ & $75.87 \pm 0.80$ & 74.07 \\
\hline MP11 & $243.9 \pm 1.72$ & $88.88 \pm 1.62$ & 86.11 \\
\hline $\mathbf{M P}_{12}$ & $250.6 \pm 1.34$ & $95.23 \pm 1.55$ & 94.44 \\
\hline
\end{tabular}

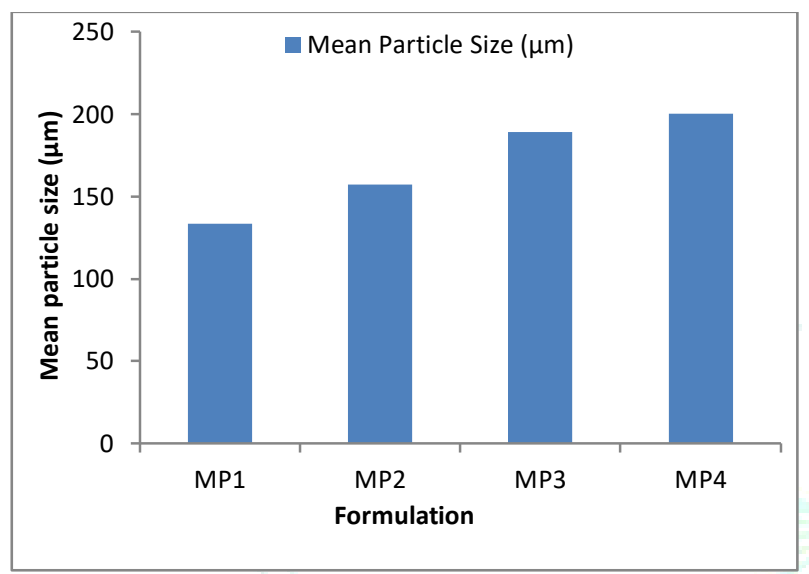

Figure 6: Mean particle size of formulations $\left(\mathrm{MP}_{1}-\mathrm{MP}_{4}\right)$

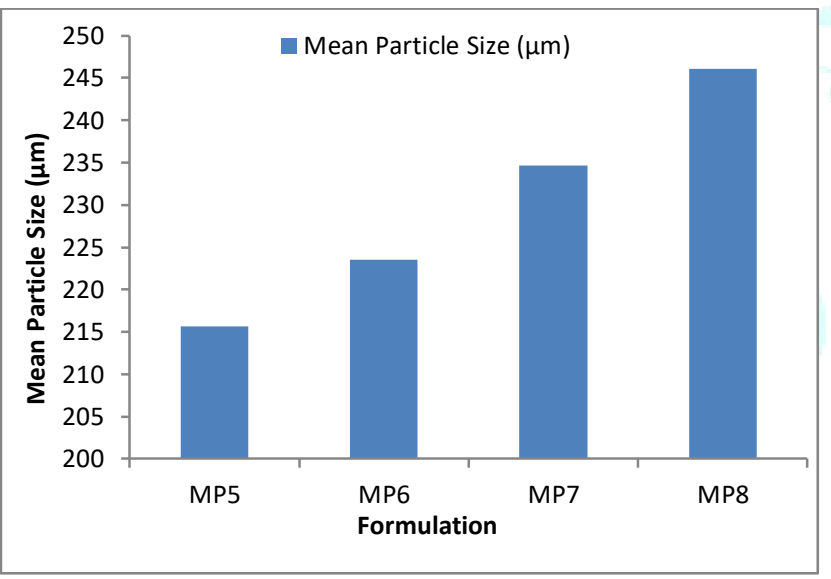

Figure 7: Mean particle size of formulations (MP5-MP8)

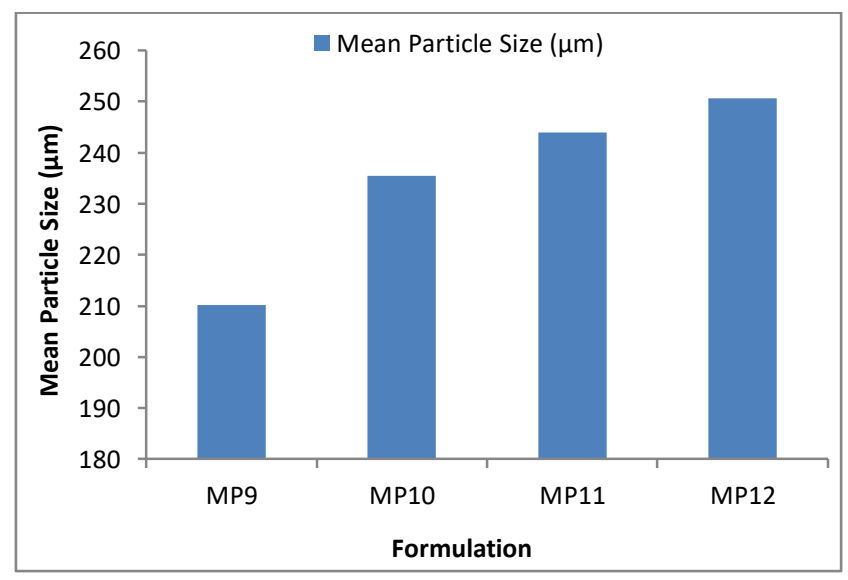

Figure 8: Mean particle size of formulation (MP9-MP12)

\section{Scanning electron microscopy}

The microspheres prepared by solvent evaporation method showed a good spherical shape, with smooth surface and the particles are distributed uniformly without any lumps as shown in the Figure 9.

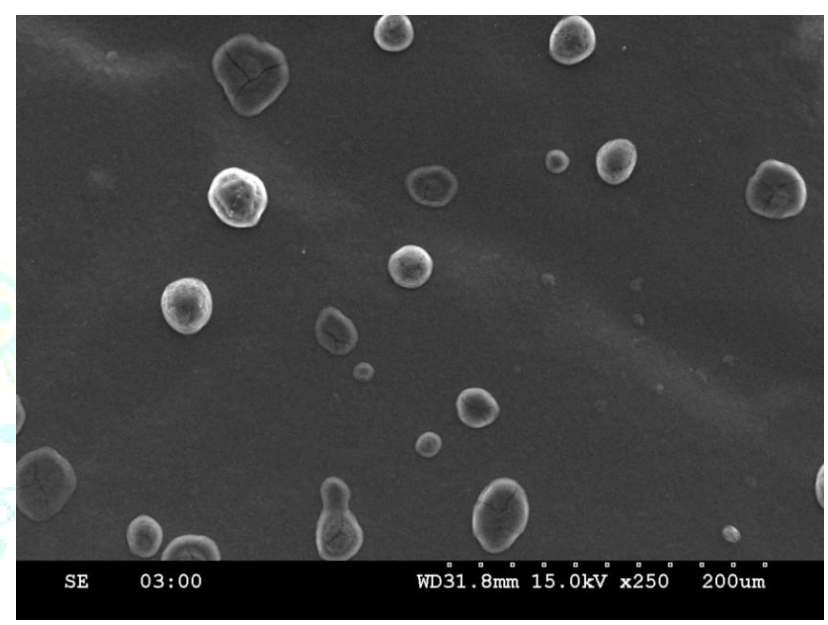

Figure 9: SEM analysis of prepared microspheres

\section{In-vitro release studies}

The in-vitro release profile of nifedipine microspheres were conducted in $\mathrm{pH} 7.4$ phosphate buffer for $12 \mathrm{hrs}$. The in-vitro drug release data for each of the formulations is shown in Figures 10-12. The cumulative percentage drug release after $12 \mathrm{hrs}$ was found to be $88.29 \%, 84.30 \%, 80.80 \%, 75.73 \%$, $70.23 \%, 66.19 \%, 61.42 \%, 58.29 \%$ for formulations $\mathrm{MP}_{1}$ to $\mathrm{MP}_{8}$ and $91.17 \%, 86.85 \%, 82.12 \%, 78.47 \%$ for formulations $\mathrm{MP}_{9}$ to $\mathrm{MP}_{12}$ respectively. The release profile was gradually decreased by increasing the polymer ratio.

From the released data observed that increase in the polymer content delays the drug release due to increased particle size and decreased surface area available for drug release. Among all the formulations prepared with ethyl cellulose polymer $\mathrm{MP}_{1}$ showed high amount of drug release i.e. (88.25\%) and among all the formulations prepared with combination of ethyl cellulose and hydroxylpropyl methylcellulose polymers MP9 showed high amount of drug release i.e. (91.23\%) in $12 \mathrm{hrs}$.

From all the twelve formulations improved drug release was observed with combination of polymers i.e. (91.23\%) as it contained both hydrophilic polymer with hydrophobic one compared to formulation prepared with ethyl cellulose i.e. $(88.25 \%)$ as it contained hydrophobic polymer. This might be due to addition of hydrophilic nature of the polymer 
which has more affinity for water results in increased thermodynamic activity of the drug in the microspheres.

At lower polymer concentration, a burst release was seen, which was more in case of ethyl cellulose and HPMC containing formulations as compared to single ethyl cellulose formulations, which may due to surface drug present on the microspheres.

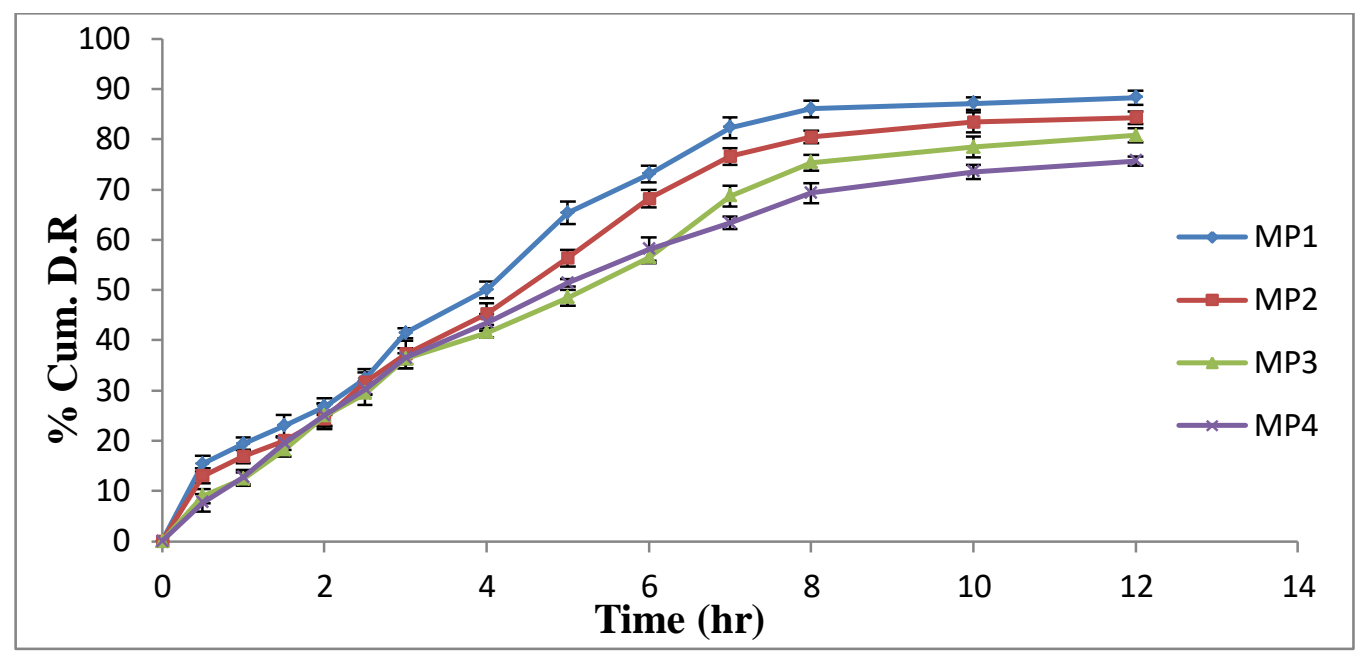

Figure 10: \% drug release of nifedipine microspheres $\left(\mathrm{MP}_{1}-\mathrm{MP}_{4}\right)$

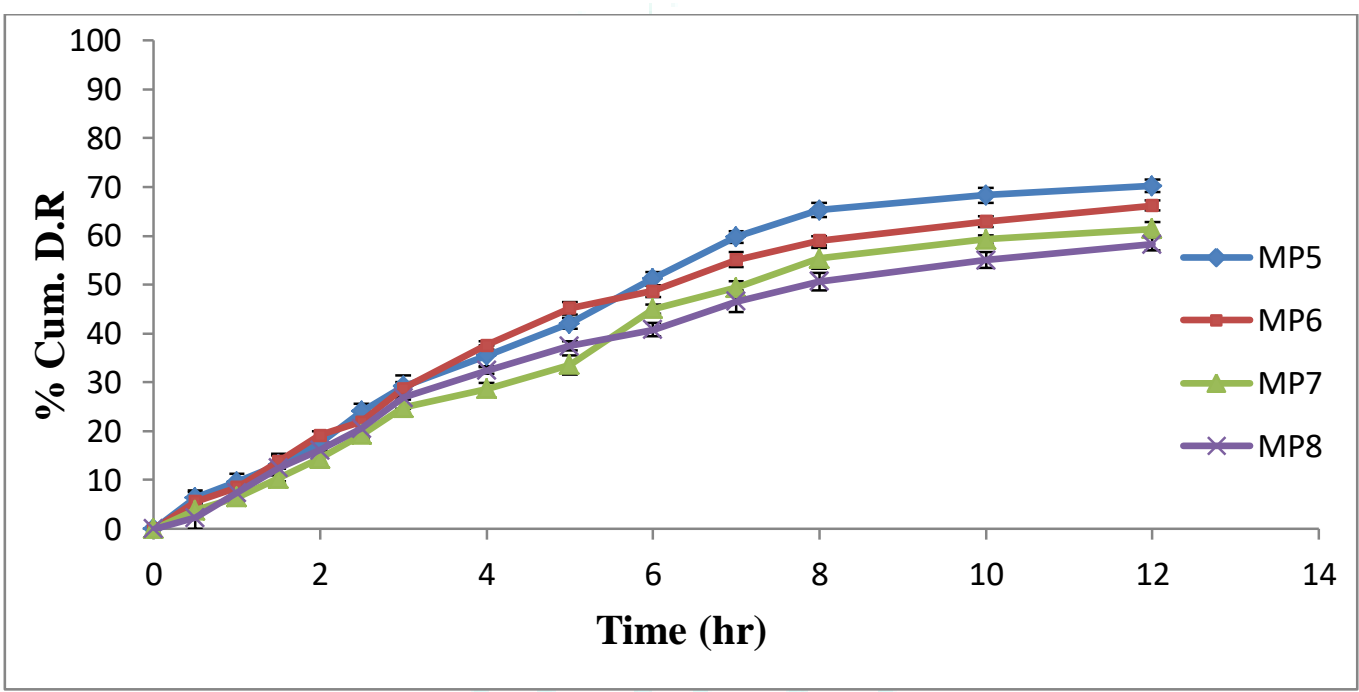

Figure 11: \% drug release of nifedipine microspheres (MP5-MP8)

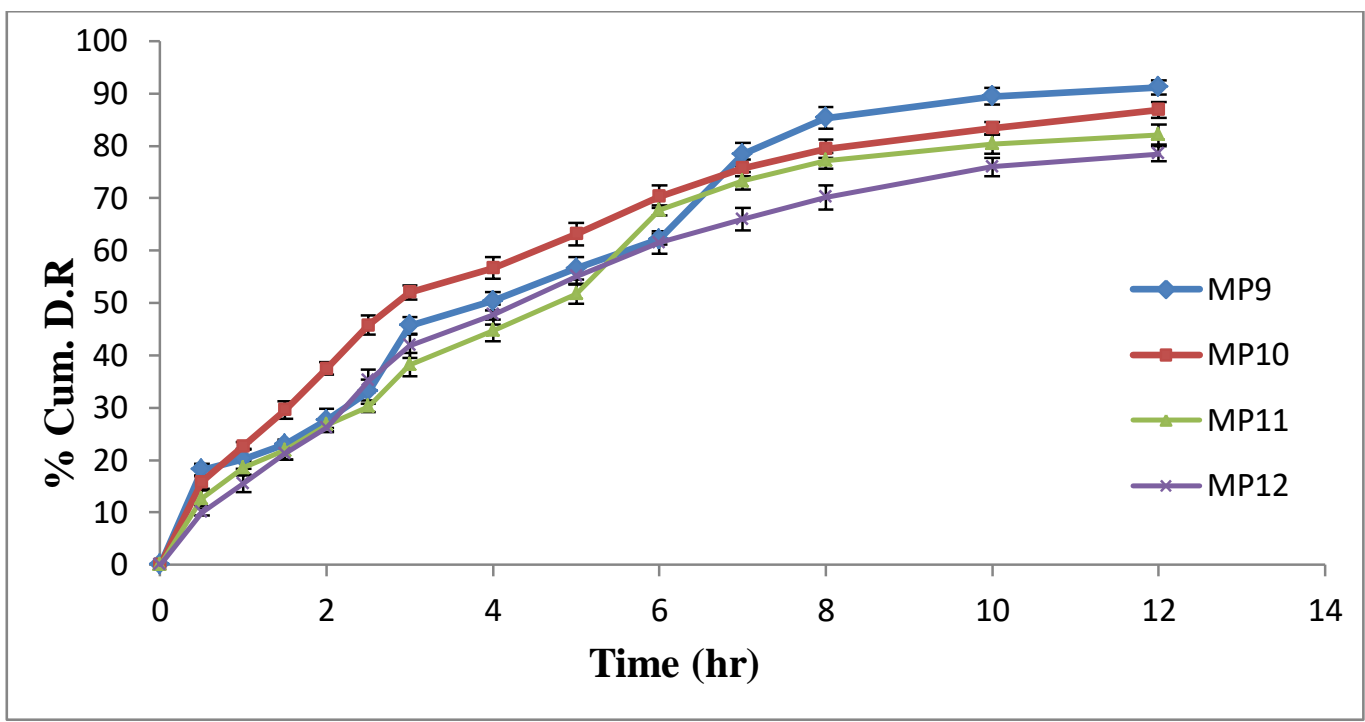

Figure 12: \% drug release of nifedipine microspheres (MP9-MP12) 
Release kinetic plots for best formulation (MP9) microspheres containing nifedipine

The kinetic data of various models revealed that formulations $\mathrm{MP}_{1}, \mathrm{MP}_{2}, \mathrm{MP}_{4}, \mathrm{MP}_{6}, \mathrm{MP}_{8}, \mathrm{MP}_{9}, \mathrm{MP}_{11}$ followed zero order release kinetics with diffusion controlled mechanism and $\mathrm{MP}_{3}, \mathrm{MP}_{5}, \mathrm{MP}_{7}, \mathrm{MP}_{10}$ followed first order release kinetics. The kinetic data of optimized formulation $\mathrm{MP}_{9}$ was shown in the Figures 13-16.

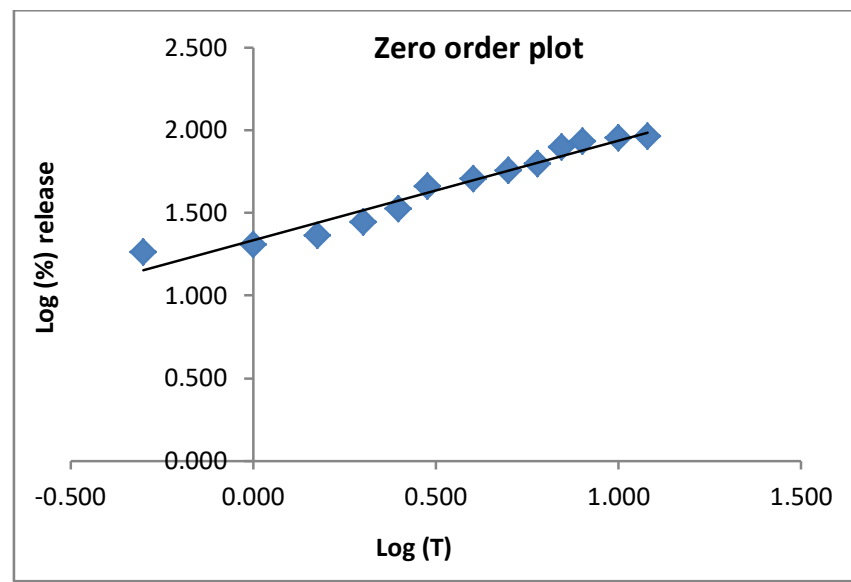

Figure 13: Plots of $\log (\mathrm{T})$ Vs Log (\%) release for formulation MP9

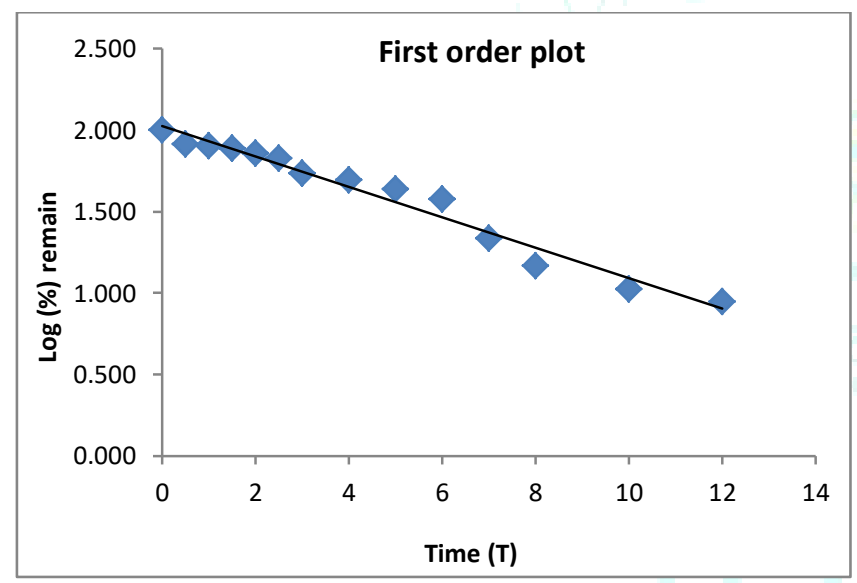

Figure 14: Plots of Time (T) Vs Log (\%) Remain for formulation MP9

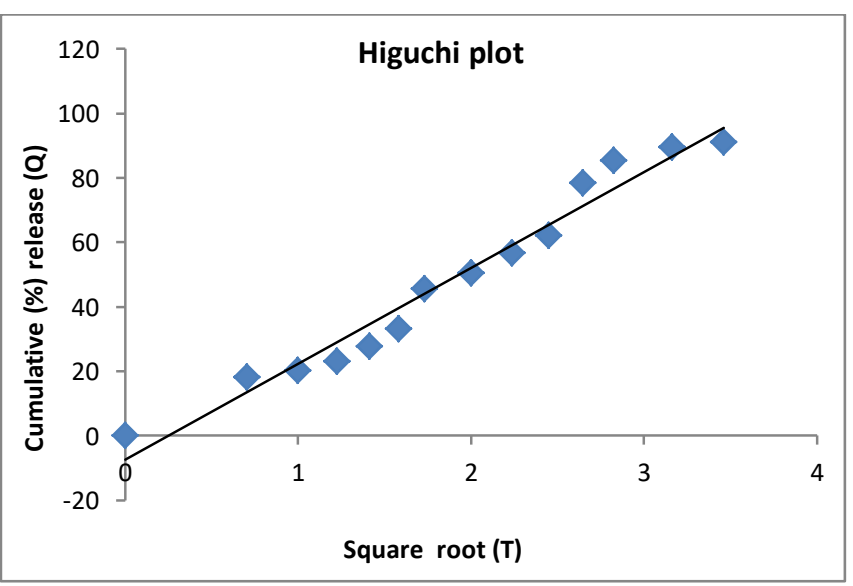

Figure 15: Plots of square root (T) Vs Cumulative (\%) release (Q) for formulation $\mathrm{MP} 9$

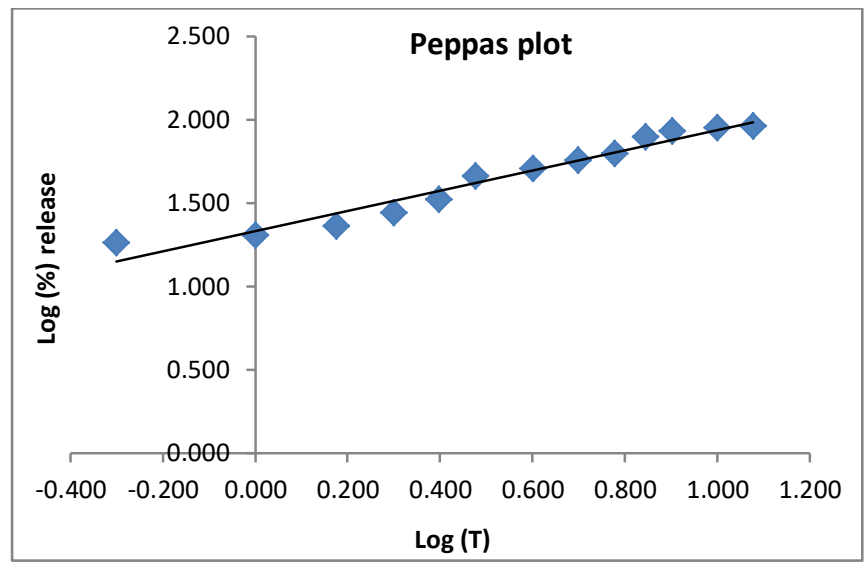

Figure 16: Plots of $\log (T)$ Vs $\log (\%)$ release $(Q)$ for formulation MP9

\section{CONCLUSION}

The present study had been a satisfactory attempt to formulate microspheres of nifedipine, an orally administered calcium channel blocker used in the treatment of angina pectoris drug with a view of improving its oral bioavailability and giving a prolonged release of microspheres with polymers such as ethyl cellulose and hydroxypropyl methylcellulose were successfully prepared by emulsification solvent evaporation method.

Based on the results obtained it can be concluded that MP9 was found to be the ideal formulation considering its size and release profile. Hence microspheres were better choice of drug delivery system than many other types of drug delivery system and plays vital role in place in novel drug delivery, particularly in diseased cell sorting, diagnostics, gene and genetic materials, safe, targeted, specific drug delivery.

\section{ACKNOWLEDGEMENT}

The authors wish to thank the management of Jangaon Institute of Pharmaceutical Sciences, Yeshwanthpur, Jangaon, Telangana, India and School of Pharmacy, Anurag Group of Institutions, Venkatapur, Ghatkesar, Telangana, India for providing necessary equipment for research, constant encouragement, praiseworthy inspiration, facilities and support.

\section{AUTHORS CONTRIBUTION}

All the authors contributed equally.

\section{CONFLICT OF INTEREST}

Author declares that there is no conflict of interest to disclose.

\section{SPONSORSHIP}

Nil.

\section{REFERENCES}

1. Alagusundaram M, Madhu Sudana Chetty C, Umashankari K, Attuluri Venkata Badarinath, Lavanya $C$ and Ramkanth $S$. Microspheres As A Novel Drug Delivery Sysytem - A Review. International Journal of ChemTech Research 2009; 1(3):52634 .

2. Satheesh Madhav NV, Kala S. Review on Microparticulate Drug Delivery System. Int J PharmTech Res 2011; 3(3):1-10.

3. Jingjun H, Rodney JW, Catherine MB, Joseph BS. Nifedipine solid dispersion in micro particles of ammonium methacrylate copolymer and Ethylcellulose binary blend for controlled drug delivery Effect of drug loading on release kinetics. International Journal of Pharmaceutics 2006; 319:44-54. 
4. Wen-Ho C, Tong-Rong T, Shu-Hui H, Thau-Ming C. Preparation and in-vitro evaluation of nifedipine loaded albumin microspheres cross-linked by different glutaraldehyde concentrations. International Journal of Pharmaceutics 1996; 144:241-5.

5. Lian-Yan W, Guang-Hui M, Zhi-Guo S. Preparation of uniform sized chitosan microspheres by membrane emulsification technique and application as a carrier of protein drug. Journal of Controlled Release 2005; 106:62- 75

6. Himabindu P, Krishna Mohan C, Nagaraj B. Design and in vitro characterization of mucoadhesive buccal patches of duloxetine hydrochloride. Int J Pharm Pharm Sci 2017; 9(2):52-9.

7. Sinha VR, Singla AK, Wadhawan S, Kaushik R, Kumria R. Chitosan microspheres as a potential carrier for drugs. International Journal of Pharmaceutics 2004; 274:1-33.

8. Sandile M, Khamanga NP, Tsitsi N, Hendry H, Roderick BW. The Evaluation of Eudragit Microcapsules Manufactured by Solvent Evaporation Using USP Apparatus. Faculty of Pharmacy, Rhodes University, Grahams town, South Africa 6140:15-22.

9. Dinarvandr, Zainali B, Atyabi F. Effects of formulation variables on nifedipine microspheres prepared by solvent evaporation technique. Daru 2001; 9:33-40.
10. Freitas S, Merkle HP, Gander B. Microencapsulation by solvent extraction/evaporation: reviewing the state of the art of microsphere preparation process technology. J Control Rel 2005; 102:313-32.

11. Gibaud S, Bonneville A, Astier A. Preparation of 3,4diaminopyridine microparticles by solvent-evaporation methods. Int J Pharm 2002; 242(1-2):197-201.

12. Trivedi P, Verma A, Garud N. Preparation and characterization of aceclofenac microspheres. Asian J Pharm 2008; 2:110-5.

13. Phutane $P$ et al. In vitro Evaluation of Novel Sustained Release Microspheres of Glipizide Prepared by the Emulsion Solvent Diffusion-Evaporation Method. J Young Pharm 2010; 2(1):3541.

14. Higuchi T. Mechanism of sustained action medication: Theoretical analysis of rate of release of solid drugs dispersed in solid matrices. J Pharm Sci 1963; 2:1145-9.

15. Korsmeyer RW, Gurny R, Doelker E, Buri P, Peppas NA. Mechanism of solute release from porous hydro-matrices and other factors may be responsible. Int J Pharm 1983; 15:25-35.

16. Himabindu P, Vasudha B, Narender B. Formulation, In Vitro and Ex Vivo Characterization of Mucoadhesive Buccal Tablets for Antihypertensive Drug. Asian J Pharm Clin Res 2018; 11(8):402-11. 